\title{
Recruiting and retaining psychiatrists
}

\author{
Sally A. Pidd
}

Abstract Recruitment and retention of psychiatrists is a major concern in commissioning and providing mental
health services. With consultant vacancies overall in the UK running at over $12 \%$ for many years,
current services are stretched and in some areas only locum provision enables them to be maintained.
This means that plans to reshape services with new teams, strengthening community-based work,
could founder. Most professions within mental health share similar difficulties. The different stages of
the career pathway of aspiring psychiatrists, from interested teenagers through to post-retirement
consultants, are described. Difficulties at each stage in attracting and retaining the most appropriate
people are discussed, and solutions at each point of the career cycle that could add up to a permanently
better staffed service and a happier workforce are offered.

Attracting and keeping enough doctors of the right calibre to maintain an effective medical presence as part of the overall mental health workforce has never been easy. Like it or not, psychiatry is regarded by many doctors as a Cinderella speciality. This has been the case since the start of the National Health Service (NHS) and remains so today, despite high levels of psychiatric morbidity and hence the need for our services in the population. Too few young doctors, it seems, see psychiatry as a desirable career option (Box 1).

The problem of adequate recruitment has been compounded over the past decade by difficulties in

\section{Box 1 Recruitment into psychiatry}

Various strategies can be used to attract students and SHOs into psychiatry:

- Getting enthusiastic young psychiatrists to promote the speciality at career fairs

- Developing promotional material targeted at graduate entrants

- Developing recruitment initiatives for those already in mental health

- Ensuring that undergraduate experiences are positive

- Identifying and nurturing interested students through to SHO posts

- Developing special study modules in psychiatry and promoting them to students

- Encouraging more pre-registration house officer posts in psychiatry retaining qualified, experienced staff. This is a problem shared by most other disciplines within mental health and, indeed, throughout the NHS generally. It has led to the situation that the Government's bold plans for reforming mental health services by investing in new teams, new types of worker and steady consultant expansion may not be fully achieved because of workforce shortages. The NHS Plan for England and Wales (Department of Health, 2000) and the National Service Frameworks covering mental health (Department of Health, 1999) and older people (Department of Health, 2001c) all have had at their core an increasing demand for a flexible, highly skilled workforce. At times, though, it seems a Herculean task to move from where we are now to this rosier picture of the future. This is despite the promises of considerable extra monies that accompanied these plans.

In this paper I explore the career pathway of psychiatrists from aspiring students to postretirement doctors, looking at the issues at each of what Brockington \& Mumford (2002), in a comprehensive paper on recruitment into psychiatry, call nodal points. Finding possible solutions at these points should over time produce the expanded and well-maintained workforce required.

\section{The wider context}

Our problems need to be set in the wider context. If we were short only of psychiatrists, then changing their work patterns and roles and going back to a more consultative and less hands-on way of working

Sally Pidd has worked as a general adult psychiatrist in the Morecambe Bay area for 20 years, and is currently based in a community mental health team in Morecambe (Victoria House, Thornton Road, Morecambe LA5 5NN, UK. E-mail: sally.pidd@mbpct.nhs.uk). Her interest in workforce issues goes back many years and she is currently Deputy Registrar (Workforce) of the Royal College of Psychiatrists. 
might be feasible. Their existing work might be passed on to others in the multi-disciplinary team. But there are not enough of practically every discipline within mental health.

The shortage of nurses within the NHS overall has been well documented (Finlayson et al, 2002). Thirty-four per cent of new graduate nurses, for example, never register to practise and within 1 year of graduation $10 \%$ are not working within the NHS. The Sainsbury Centre for Mental Health's (2000) review of recruitment and retention in mental health care highlighted that $85 \%$ of the NHS trusts surveyed were struggling to find and keep mental health nurses. High levels of emotional exhaustion were found in both hospital and community-based staff. In 1997, there was a $10 \%$ vacancy rate for occupational therapists and a failure to match the workforce demands with the output from training courses. However, there is a continuing shortage of posts for clinical psychologists in the NHS, despite a steady growth in their numbers: relatively unusually for a discipline, the demand for training places far outweighs the opportunities on offer. The picture for mental health staff as a whole is not positive and it can result in a cycle of frustration for both health care staff and service managers (Fig. 1).

Plugging gaps with locum staff, either in the short or long term, is both expensive and unsatisfactory for services that, above all, require continuity. However, faced with vacancy rates of upwards of $12 \%$ overall for consultant psychiatrists, as shown in the College's 2001 annual census (Royal College of Psychiatrists, 2002), trusts have few alternatives if they wish to maintain services. When most posts advertised attract only one or two candidates suitable for shortlisting, prospects for changing things can seem gloomy.

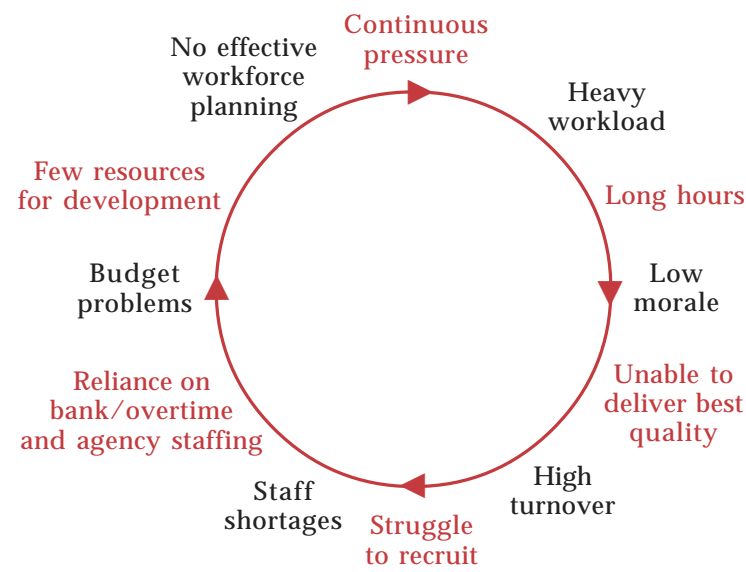

Fig. 1 The cycle of staffing frustration. After Sainsbury Centre for Mental Health (2000), with permission.
This problem is not confined to the UK. A brief trawl through the internet, searching on PSYCHIATRIC and WORKFORCE and SHORTAGES brought up over 1500 references from around the globe. If the president of the American Psychiatric Association (Eist, 1997) could express the view that the USA, probably with the highest number of psychiatrists per head of population in the world, could still not deliver the service needed across the country, we in the UK are likely to struggle to move up from a much lower base. For all these reasons, following the publication of the National Service Framework for Mental Health, the Department of Health created the Workforce Action Team to look at staffing implications across the board. The team's final report explored in great detail the work that needed to be done (Department of Health, 2001d).

\section{Attracting students into psychiatry}

This is a two-stage process. First, more students with positive attitudes to psychological approaches and psychiatry in general need to be targeted. Second, the interest of these students once they are at medical school must be maintained and cultivated.

Until recently, the standard route into medical school in the UK was via good science qualifications, and the process was thought to be highly competitive. The situation is changing. McManus (2002) reported that the selection ratio, i.e. the number of applicants for each place, fell from 2.11 in 1995 to 1.55 in 2000. Fortunately, the author found indications that the trend may be reversing, as in 2002 there was a $13 \%$ increase in applicant numbers. With the rapid expansion in medical school places that will follow the opening of five new medical schools across the UK by 2005, many more people will need to be drawn into the potential pool of future doctors. The relative lack of male applicants (women now outnumber men on most courses) may have significant implications for the numbers of doctors likely to be active in the workforce over their longer-term careers. Introducing government-initiated graduate-entry fast-track programmes will change the profile of new doctors over time. According to the Universities and Colleges Admission Service, out of 14000 applicants to study medicine in 2003, nearly 3000 were for these fast-track programmes, and the growing problem of student debt does not appear to have been a deterrent.

\section{Attracting medical students into psychiatry}

Medical schools have always varied in the proportion of graduates who express an interest in 
psychiatry as a career and then convert this into taking up senior house officer (SHO) training. Similarly, the amount of time devoted to psychiatry in the curriculum varies, as does its delivery. Overall, time spent in direct contact with mental health services is probably decreasing. In any case, the figures show a shortfall in meeting the numbers needed to fully staff the workforce from UK graduates and so the very heavy reliance on overseas doctors will continue (Brockington \& Mumford, 2002).

\section{Opportunities for recruiting students into medicine}

The increase in medical school places and introduction of graduate-entry training give rise to opportunities to improve recruitment. A wider pool of potential applicants and a higher number of mature graduates might help to draw in those with more interest in psychological approaches. Psychiatrists need to be proactive both locally and centrally (at the Royal College of Psychiatrists) to promote enthusiastically careers in the speciality to conventional A-level students and to older individuals. When questioned at a sixth-form conference, students interested in applying to medical schools rated psychiatry as highly as medicine as a potential career objective (Maidment et al, 2003). We need to capitalise on findings like these. Better promotional materials and programmes of work-shadowing of doctors by potential applicants, who may already be working in related fields such as nursing, also need to be developed.

\section{Opportunities for recruiting medical students into psychiatry}

For medical students showing an interest during psychiatric placements, the offer of optional specialstudy modules, mentoring by enthusiastic consultants or specialist registrars and encouragement to enter training schemes by maintaining regular contact may pay dividends. The development of more pre-registration house officer posts in psychiatry will help to give more young doctors an exposure to the work as a taster. Such posts have existed in Sheffield for many years (O'Dwyer, 1999) and a newer scheme in the London Deanery (Herzberg et $a l, 2003$ ) seems to have attracted trainees interested in general practice or psychiatry and helped to consolidate these possible career intentions.

Selling the merits of flexible, family-friendly working practices within the speciality is important. Doing so might also encourage both women and men who want a life outside medicine as well as job satisfaction within it to consider psychiatry as the best fit for a holistic practice that is both challenging and rewarding. Variations of these approaches are being adopted in countries such as Canada and Australia, and we can learn from others' experiences (Weintraub et al, 1999).

Over 20 years ago a symposium was run by the Association of Psychiatrists in Training entitled 'Who puts medical students off psychiatry?' Many of its findings are still applicable today and it should be seen as the responsibility of the whole profession to attract the brightest and best, kindle their interest and convert them into future psychiatric colleagues (Creed, 1979).

\section{Retention issues for senior house officers}

Attracting doctors into $\mathrm{SHO}$ posts in psychiatry is relatively easy. Adverts regularly bring in over 100 applicants for many (but not all) schemes. Ensuring that a large proportion of them stay the course, pass the MRCPsych examinations and enter higher training is proving harder. The attrition rate of $\mathrm{SHOs}$ in some schemes is over $50 \%$. Some loss is for good reasons. Many posts, up to $25 \%$ or more in some areas, are occupied by general practice trainees. That improves the overall skills in mental health in the general workforce, so it should be seen positively. But there remains a significant drop-out of doctors whose stated intention at the onset of training is to become psychiatrists. Finding out why they subsequently change their minds has been the focus of a number of research endeavours. These have included Cox et al's (2000) survey of SHOs who passed Part I of the MRCPsych, but failed to obtain Part II; ongoing research in Wales (Clarke-Smith \& Tranter, 2002); and a set of linked research projects carried out by the College Research Unit under the overall title of Career Intentions in Psychiatric Trainees and Consultants (CIPTAC) (http://www. rcpsych.ac.uk/cru/complete/workforce $\% 20$ planning.htm).

The findings of these studies are similar. Doctors chose to come into psychiatry because of its holistic emphasis, multi-disciplinary patterns of working and, crucially, their enjoyment of their undergraduate experience. They stayed on for similar reasons. Those disenchanted with the speciality cited as a major concern the quality of the relationship between consultant and trainee; poor-quality supervision was also a great deterrent. Those failing to progress to higher training were critical of the level of support given in examination preparation, and in some areas of the country SHOs felt that there 
was inequitable access to speciality posts within rotations.

Senior house officers were unhappy about the depressing conditions in which they work and their patients live. The patient-mix on acute admission wards, with high numbers of challenging patients and inadequate staffing, made some feel unsafe. Again in some areas of the country, they felt that they had unmanageable case-loads or were expected mainly to act as clerks on in-patient units.

Overall, though, it seems that their observation of low morale in their consultants and in other staff might be a significant disincentive to progressing in psychiatry.

\section{Key issues for training schemes}

Trainees need good, varied, well-supervised posts. They need to feel safe at work and they need good role models. They need support in preparing for examinations and would benefit from positive mentoring from older peers. The working environment needs to be improved for patients and staff alike (Griffiths, 2002). These issues are being tackled in different ways. The College is continuing with rigorous inspection of training schemes, giving a high emphasis to safety issues. The Department of Health has provided more money to improve the state of in-patient units, but much more needs to be achieved in this area. Being an educational supervisor needs to be seen as a privilege, not a right, so that enthusiastic trainers not currently able to have $\mathrm{SHO}$ posts could take over from consultants who, for whatever reason, are providing inadequate training and supervision opportunities (Box 2).

Many in the profession feel that an expansion of the SHO grade in psychiatry is essential. However, this is unlikely to happen, mainly because of the high proportion of overseas graduates already in $\mathrm{SHO}$ posts across all specialities. Better use, therefore, needs to be made of existing posts,

Box 2 Key messages from SHOs about training

- They want good, regular supervision

- They want to work in safe, pleasant environments

- They want exposure to varied posts in training schemes, including more specialities

- They want to work with enthusiastic, positive consultants

- They want to see a future in do-able jobs at the end of training using a higher proportion for trainees intending to become psychiatrists and giving them a better deal once in post.

\section{Specialist registrars}

The main problem with specialist registrars (SpRs) is that there are insufficient SHOs passing the MRCPsych examinations to fill the available national training numbers. Successful renegotiation and increase in national training numbers for general adult psychiatry, the speciality with the highest number of unfilled consultant posts, has not been matched by $100 \%$ occupancy. Fully funding posts from postgraduate deanery monies over the past 2 years, rather than relying on trusts to pay $50 \%$ (which was the previous position in England and Wales) has not made enough of a difference. There is also a marked variation in the attractiveness of specialities, with for example little problem in attracting psychotherapy recruits, but major difficulties in filling learning disability posts.

High numbers of trainees opting for dual training leads to longer overall training times and also difficulty in predicting their eventual speciality choice. The rise in the number of 'flexible' trainees (those on flexible training programmes), especially in child and adolescent posts, and the high proportion of women in this and other specialities can lead to very extended training times. The European Union requirement for exact pro rata training times can leave flexible SpRs training too long to achieve their Certificate of Completion of Specialist Training (CCST) and this may be offputting for them.

The final issue is that there is a growing trend for doctors who have obtained College membership to opt for non-consultant career grade (NCCG) posts rather than continue into higher training. This reduces further the pool of future consultants, although it has a positive effect in the workforce elsewhere.

\section{Solutions}

Possible solutions at this point in the career ladder include mentoring of SHOs through into higher training by good role models. While in post, good peer group support mechanisms are valuable, with time given for all SpRs to meet regularly. Making the annual review process (the 'record in training assessment' - RITA) a positive, encouraging and supportive experience, as well as highlighting further training needs, should help. Mechanisms are needed to enable NCCG doctors back onto the training ladder at whatever stage they left it. 
However, the single most important step is probably to make consultant posts look attractive and do-able. Currently, SpRs see at close quarters how far from that many of their educational supervisors' posts are. They are intelligent enough to see through overoptimistic consultant job descriptions and can take their time over choosing jobs. They also can, and do, move on from consultant posts that prove unmanageable, so wasting recruitment effort and increasing the lack of service continuity. Trusts need to take more care in drawing up honest, workable job descriptions (Royal College of Psychiatrists, 2003).

\section{Consultants}

The problems in retaining consultants are well known. Being able to retire at 55 with mental health officer status means that few remain in post until 65 , and it seems that most consultants are likely to be seriously thinking of retiring by 60 . Kendell's survey of consultants who had retired early (Kendell \& Pearce, 1997) painted a clear picture of a fairly demoralised group. Probably the same situation exists today and the CIPTAC studies referred to above will yield more up-to-date information in this area. Similar findings apply across the board in medicine (Davidson et al, 2002). The main pressures for consultants contemplating giving up their consultancy are high case-loads, excessive bureaucracy, lack of resources and problems with management, including the existence of a 'blame culture'. Despite this, the majority of consultants still say they enjoy their work and it is clear that many are prepared to work post-retirement in some capacity in mental health. The low morale highlighted by Kendell \& Pearce relates more to existing conditions than to the consultant role as it could be.

This issue of consultant roles and working styles has been explored in studies in which existing consultants have been interviewed and the types of posts that lead to higher job satisfaction have been examined (e.g. Kennedy \& Griffiths, 2000). The development of new teams such as assertive outreach, crisis resolution and early intervention in psychosis may give jaded psychiatrists an opportunity to move into new spheres in later stages of their career. Anecdotal evidence gathered from contributors to a discussion on this topic at the College's Faculty of General Adult Psychiatrists annual meeting in 2002 suggests that, in some areas, this has perhaps led to difficulty in filling key posts for sector psychiatrists within community mental health teams, meant to be the foundation of services.

The persistent high vacancy rates in some areas have led to a dependence on locums, who can command very high salaries, have varying levels of experience and may not take on all the work associated with substantive posts. This can lead to disquiet and lower morale among existing consultants and has led to a worrying trend of CCST holders delaying the move into consultant posts by sampling jobs as locums first. This may be useful and lucrative for them, but it does not help in the longer-term filling of established or new posts.

\section{Solutions}

In the short term, there are posts that need to be filled. Initiatives to recruit from overseas are ongoing. Despite efforts to concentrate these recruitment drives on and from countries thought to overproduce doctors, concerns about this approach include the fact that the doctors attracted are often from countries that need their skills more than the UK does, and this raises major ethical issues (O'Neale, 2002). Once these doctors are in post, however, good mentoring will help to integrate them into services and if this means that these are then fully staffed it can alleviate some of the pressures illustrated in Fig. 1.

Recent Department of Health initiatives apply to consultants as much as to other NHS staff. Improving Working Lives (Department of Health, $2001 b$ ) has the aim of providing well-managed flexible working environments that both support staff and respect their need for a balance between work and their home life. The NHS Childcare Strategy aims to increase the number of on-site nurseries for the very young and before-school and after-school clubs for school-age children. Flexible Career Schemes (introduced at the endof 2002) is a fully funded programme allowing doctors to take a break from full-time working while retaining their clinical skills (Department of Health, 2003). The Changing Workforce Programme is encouraging the development of new roles and ways of working for consultants (Department of Health, 2001a).

Making sure that doctors are aware of all these possibilities at every stage in their careers may make the best use of fully trained doctors in a way that matches both their age and family commitments (Paice, 2001).

\footnotetext{
Case study - one flexible working life

Dr W came to medicine late via an Arts degree. She was in her 30s before starting as a clinical assistant in psychiatry. She then worked as a part-time trainee, eventually passing MRCPsych Part II by her early 40s. She gained a wide variety of experience through less-formal training, including time as a senior registrar en route to a part-time consultant post in general adult psychiatry at the age of 47 .

She remained part time, increasing her sessions and eventually moving wholly into old age work.
} 
She developed other special interests and by 65 felt she still had enough enthusiasm to contribute to services. Her replacement wanted to work fewer sessions so she made up the rest, continuing with a memory clinic she had established. She also offered mentoring to a younger colleague returning from extended sick leave. She gave up the increasingly onerous on-call duties and is now able to enjoy the work she is doing, is not bored and her skills are being used.

\section{Consultant retention}

It is essential that trusts that wish to retain the doctors they have should value their consultants, providing them with good working conditions and offering sabbatical leave when appropriate, as well as the possibility of training for new roles.

In a project led by Judy Curson, the Department of Health's Medical Workforce Review Team, supported by the statistics section of the Department of Health in England, has developed a computer model to simulate workforce requirements for every speciality. Running that model for psychiatry shows that the quickest way of bringing vacancy rates down would be to retain existing consultants for a few years longer, rather than increasing training grade numbers, which takes much longer to affect workforce expansion (J. Curson, personal communication, 2003).

New posts need to be do-able (and not just by the superhuman). Making sure that new posts are in line with the College's norms might help to achieve this (Royal College of Psychiatrists, 2003). Existing posts may need to be reviewed to ensure that their holders are not left disadvantaged by old styles of working when new consultants have been able to negotiate better jobs. Untenable posts lead to premature retirement. Allowing consultants to vary their job plans according to their domestic commitments and their age would help to retain their skills and use them in new ways. Finally, generating a supportive, non-blaming management culture would help everyone. Recognition that risk assessment is not an exact science and that even the most competent can get it wrong at times would alleviate much of the pressure of day-to-day practice.

\section{Conclusion}

For some psychiatrists all these changes and possible solutions will have come too late: as one respondent to Kendell \& Pearce's survey said, 'Nothing would persuade me to stay on'. But for others, those who we hope are joining the profession in the future, are currently training or are running services, psychiatry still offers many challenges. It is a scientifically credible part of medicine, working within a holistic framework, that still provides the ultimate reward of making a positive difference to the lives of those suffering from mental illness or living with psychological distress.

Studs Terkel, in his classic book Working (Terkel, 1972), talks about how it should be:

'Work as a search for daily meaning as well as daily bread, for recognition as well as cash, for astonishment rather than torpor, in short for a sort of life, rather than a Monday through Friday sort of dying.'

Making positive changes at each stage of the career pathway will, hopefully, give the numbers and quality of doctors we need to make work that gives us all more than a 'sort of life' and gives our patients the service they deserve.

\section{References}

Brockington, I. F. \& Mumford, D. B. (2002) Recruitment into psychiatry. British Journal of Psychiatry, 180, 307-312.

Clarke-Smith, L. \& Tranter, R. (2002) Recruitment and retention in psychiatry (letter). British Journal of Psychiatry, $181,163$.

Cox, J. L., Ryan, M. \& Hanna, M. (2000) Reasons for dropping out: a survey of tutors and trainees opinions. Parapraxis, 6, 5-10.

Creed, F. (1979) Who puts medical students off psychiatry? Welwyn Garden City: S K \& F publications.

Davidson, J. M., Lambert, T. W., Goldacre, M. J., et al (2002) UK senior doctors' career destinations, job satisfaction, and future intentions: questionnaire survey. $B M J, 323,685-686$.

Department of Health (1999) A National Service Framework for Mental Health. London: Department of Health.

- (2000) The NHS Plan. A Plan for Investment, a Plan for Reform. http: / /www.nhs.uk/nationalplan/

- (2001a) Changing Workforce Programme. Briefing Paper. London: Department of Health.

— $(2001 b)$ Improving Working Lives. http://www.doh. gov.uk/iwl

Department of Health (2001c) A National Service Framework for Older People. London: Department of Health.

- (2001d) Workforce Action Team Final Report. http:// www.doh.gov.uk/mentalhealth/watmainreport.pdf

- (2003) Flexible Career Schemes. http://www.nhscareers. nhs.uk//nhs-knowledge_base/data/5455.html

Eist, H. (1997) Psychiatric workforce: there aren't enough psychiatrists. Psychiatric News, 17 January. http:// www.psych.org/pnews/97-01-17/pres.html

Finlayson, B., Dixon, J., Meadows, S., et al (2002) Mind the gap: the extent of the NHS nursing shortage. BMJ, 325, 538-541.

Griffiths, H. (2002) Acute wards: problems and solutions. Their fall and rise. Psychiatric Bulletin, 26, 428-430.

Herzberg, J., Aitken, M. \& Moss, F. (2003) Pre-registration house officer training in psychiatry: the London experience. Psychiatric Bulletin, 27, 192-194.

Kendell, R. E. \& Pearce, A. (1997) Consultant psychiatrists who retired prematurely in 1995 and 1996. Psychiatric Bulletin, 21, 741-745.

Kennedy, P. \& Griffiths, H. (2000) An Analysis of Concerns of Consultant General Psychiatrists about Their Jobs. Durham: Northern Centre for Mental Health.

Kennedy, P. \& Griffiths, H. (2001) General psychiatrists discovering new roles for a new era ... and removing work stress. British Journal of Psychiatry, 179, 283-285.

McManus, I. C. (2002) Medical school applications - a critical situation. BMJ, 325, 786-787.

Maidment, R., Livingston, G., Katona, M., et al (2003) Carry on shrinking: career intentions and attitudes to psychiatry 
of prospective medical students. Psychiatric Bulletin, 27, $30-32$.

O'Dwyer, J. M. (1999) Psychiatric training of pre-registration house officers. Psychiatric Bulletin, 23, 283-285.

O'Neale, J. (2002) Stealing doctors. Triple Helix, Autumn, $14-16$.

Paice, E. (2001) Women in hospital medicine. Clinical medicine. Journal of the Royal College of Physicians of London, 1, 344-345.

Royal College of Psychiatrists (2002) Annual Census of Psychiatric Staffing 2001 (Occasional Paper OP54). London: Royal College of Psychiatrists.

- (2003) Model Consultant Job Descriptions and Recommended Norms (Occasional Paper OP55). London: Royal College of Psychiatrists.

Sainsbury Centre for Mental Health (2000) Finding and Keeping: Review of Recruitment and Retention in the Mental Health Workforce. London: Sainsbury Centre for Mental Health.

Terkel, S. (1972) Working: People Talk About What They Do All Day And About How They Feel About What They Do. New York: The New Press.

Weintraub, W., Plaut, S. \& Weintraub, E. (1999) Recruitment into psychiatry: increasing the pool of applicants. Canadian Journal of Psychiatry, 44, 473-477.

\section{Multiple choice questions}

1 Recruiting and retaining an effective psychiatric workforce:

a is only a problem for doctors

$\mathrm{b}$ is a major issue in most developed and developing countries

c would be helped in the short-term by increasing $\mathrm{SHO}$ numbers

d requires attention to possible solutions at every stage of the career pathway

e should be helped by encouraging new styles of working for existing consultants.

2 For aspiring medical students:

a the only acceptable route into medicine is via good science A-levels or equivalent

b new fast-track graduate entry programmes are proving popular c the number of medical school places in the UK will double between 2002 and 2005

d more males than females are applying for places

e targeting mature entrants to courses with information about mental health careers may encourage recruitment into psychiatry later.

3 For doctors in the SHO grade in psychiatry:

a only a minority expect to become consultant psychiatrists

b a major attraction to a psychiatric career is the multidisciplinary working

c working in a safe environment is a key issue for retention on the career pathway

d they would have had little competition to obtain their posts

e using psychiatric SHO posts for general practice trainees should help to improve the quality of mental health care overall.

4 For consultant psychiatrists:

a the majority continue working until the normal retirement age of 65

b most are happy with their current workloads

c increased bureaucracy is a commonly cited reason for wanting to retire early

$\mathrm{d}$ few intend to do any mental health work after retirement

e flexible patterns of working throughout consultant careers would help to retain experienced staff longer.

\section{MCQ answers}

$\begin{array}{lllll}\text { 1 } & & \text { 2 } & 3 & 4 \\ \text { a F } & \text { a F } & \text { a F } & \text { a F } \\ \text { b T } & \text { b T } & \text { b T } & \text { b F } \\ \text { c F } & \text { c F } & \text { c T } & \text { c T } \\ \text { d T } & \text { d F } & \text { d F } & \text { d F } \\ \text { e T } & \text { e T } & \text { e T } & \text { e T }\end{array}$

\section{INVITED COMMENTARY ON Recruiting and retaining psychiatrists}

Sally Pidd's article (2003, this issue) gives a structured analysis of the key issues and some potential solutions to recruitment and retention problems in psychiatry. My perspective on this is influenced by personal experiences. These include my own career, my involvement with the Collegiate Trainees' Committee, and hearing the views of students, peers and consultants.

\section{Why do people enter psychiatry?}

One of the attractions of psychiatry is that it encompasses a wide range of perspectives and treatment approaches. A broad range of experience in staff is also valued. My experiences of working in accident and emergency and in New Zealand were viewed positively at my specialist registrar (SpR) interview. 